\title{
Integração do sistema de gestão ambiental no sistema de gestão de qualidade em uma indústria de confecções
}

\author{
Integration of the environment management system into \\ the quality management system in an apparel company
}

\author{
Eloi Brendler ${ }^{1}$ \\ Luciana Londero Brandli ${ }^{2}$
}

\begin{abstract}
Resumo: A integração dos sistemas de gestão de uma organização em um único sistema tem sido uma estratégia adotada por várias empresas, especialmente no que se refere à qualidade e gestão ambiental. O objetivo deste artigo é apresentar a estruturação do sistema de gestão ambiental a partir do sistema de gestão de qualidade para uma empresa do ramo de confecções, apontando assim as facilidades e dificuldades do sistema de gestão integrada. A pesquisa foi desenvolvida em uma empresa do ramo de vestuário feminino. A empresa produz cerca de 500.000 peças por mês. Esta empresa foi escolhida para a pesquisa, pois estava no final do processo de certificação ISO 9001. A pesquisa foi desenvolvida por meio da estratégia de pequisa-ação. Os resultados são apresentados com base na implementação dos requisitos de ambas as normas, na análise daquilo que foi incorporado no SGA a partir do aprendizado do SGQ, daquilo que foi integrado, e do que não houve influência. Também são descritas todas as etapas de implantação do SGA com base no SGQ. As conclusões reforçam a existência de vantagens e desvantagens da integração, a necessidade de se avaliarem as especificidades de cada empresa, de cada sistema de gestão.
\end{abstract}

Palavras-chave: Gestão Integrada. Sistema de Gestão Ambiental. Sistema de Gestão de Qualidade. Confecção têxtil.

\begin{abstract}
Integrating management systems in an organization has been a strategy adopted for some companies, especially with respect to quality and environment management systems. The objective of this study is to present the structure of the environment management system based on the quality management system of an apparel company in order to identify the integrated management system difficulties and facilities. The research was carried out in a company in the feminine clothing segment. This company was chosen because it was at the end of the process for achieving ISO 9001 certification. The present study was conducted using action research strategy. The results are presented based on the implementation of the requirements of both norms, the analysis of what features of the QMS were incorporated into the EMS, what was integrated, and what did not exert any influence. The conclusions highlight the advantages and disadvantages of this integration and the need to evaluate the particularities every company and system of management.
\end{abstract}

Keywords: Integrated management. Environment Management System. Quality Management System. Apparel Company.

\section{Introdução}

A indústria têxtil brasileira é caracterizada pela sua heterogeneidade, no que se refere ao porte, à linha de produtos e ao estágio tecnológico e gerencial, sendo que na confecção é grande o grau de verticalização (GAZETA MERCANTIL, 1999). Lorenzi (2007) revela que o setor têxtil cresceu mais de $0,99 \%$ no primeiro semestre de 2007, acumulando um crescimento de $1,80 \%$ nos últimos anos, indicando o aumento da produção têxtil e podendo considerar este setor como fundamental para a economia brasileira.

Além disso, o Brasil está na lista dos 10 principais mercados mundiais da indústria têxtil, bem como entre os maiores parques fabris do planeta, sendo o segundo principal fornecedor de índigo e o terceiro de malha. O Brasil figura entre os cinco principais países produtores de confecções e é hoje, um dos oito grandes mercados de fios, filamentos e tecidos (ASSOCIAÇÃO..., 2008).

Segundo Melo (2005), as indústrias têxteis e de confecções refletem um valor econômico-social, absorvendo uma quantidade de mão de obra representativa. Situa-se na economia brasileira, dentre os 24 setores de atividades industriais, no quinto lugar em empregos diretos e no sexto em faturamento.

\footnotetext{
${ }^{1}$ Departamento de Administração, Universidade Regional Integrada do Alto Uruguai - URI, E-mail: brendler@brendler.com.br

2 Programa de Pós-graduação Infraestrutura e Meio Ambiente, Universidade de Passo Fundo - UPF, Rod. Acs Campus

Universitário, s/n, Km 171, Bairro São José, Passo Fundo, RS, E-mail: brandli@upf.br
}

Recebido em 29/4/2010 — Aceito em 20/12/2010

Suporte financeiro: Nenhum. 
As indústrias de confecção brasileiras vêm passando por várias transformações na produção, no que se refere à modernização tecnológica do seu parque industrial, na busca de novas matérias-primas, na melhoria da qualidade, na racionalização de energia, no desenvolvimento de produtos pioneiros para o mercado e na excelência de sua mão de obra direta e administrativa. Todos estes esforços têm um único objetivo: reduzir custos para ganhar competitividade no mercado mundial.

Ao analisarem a competitividade da Indústria Têxtil na Região Nordeste e no Brasil, bem como seus gargalos, potencialidades e desafios, os autores Viana, Rocha e Nunes (2008) indicam que os chamados sistemas integrados de gestão, como tendência observada mundialmente, podem facilitar o gerenciamento no ambiente globalizado e competitivo desta indústria. Conforme o Centro de Qualidade, Segurança e Produtividade - QSP (2008), nas empresas certificadas com a ISO 14000 no Brasil, 94\% declararam possuir também certificação na norma internacional de qualidade ISO 9001, aliás, a primeira a ser adotada em $87 \%$ delas. Apenas $7 \%$ tiveram a ISO 14000 como primeiro certificado e só $6 \%$ as receberam simultaneamente. Entre as empresas certificadas, $65 \%$ integraram os sistemas de gestão, na maior parte dos casos de ambiente e qualidade.

Nesse sentido, a integração dos processos ambientais com os da qualidade é um desafio para que ambos contribuam simultaneamente na construção da melhoria contínua da organização, de seus produtos e serviços.

Apesar de se encontrarem autores que se posicionam quanto às vantagens da integração dos sistemas de gestão, como sintetizam o artigo de Khanna, Laroyia, Sharma, (2009), a descrição de um caso prático é importante, pois contribui com novos argumentos e reforçam os existentes. Além disso, mesmo já existindo casos de integração de sistemas de gestão (GRAEL; OLIVEIRA, 2010; CHAIB, 2005), a apresentação de um estudo de caso da indústria de confecções pode contribuir tanto para o setor quanto para a academia.

Aliado a isto, a empresa deste estudo, quando estava no final do processo de certificação da qualidade, percebeu a necessidade de implementar um sistema de gestão ambiental de maneira formal. Assim, se construiu a questão de pesquisa: como estruturar um SGI entre a NBR ISO 14001:2004 e NBR ISO 9001:2008 em uma empresa de confecções, balizado no SGQ já implementado?

Neste contexto, o objetivo deste artigo é apresentar a estruturação do Sistema de Gestão Ambiental (SGA) a partir do Sistema de Gestão de Qualidade (SGQ) para uma empresa do ramo de confecções, apontando assim as facilidades e dificuldades do sistema de gestão integrado.

\section{Abordagem integrada dos sistemas de gestão}

Os sistemas de gestão (SGs), sejam eles da qualidade (ISO 9001:2008), meio ambiente (ISO14001:2004), saúde e segurança do trabalho (OHSAS 18001:2007), responsabilidade social (SA 8000), gestão de riscos (ISO 31000:2010) e outros, têm como base as diretrizes das normas. Todas estas normas possuem um grande número de similaridades que facilitam a integração destes sistemas, isto porque vêm sendo trabalhadas por meio de revisões e novas edições para esta finalidade, no sentido de facilitar a sua implementação (ASSOCIAÇÃO..., 2004, 2008b, 2010; BRITISH..., 2007). Embora um padrão para SIG não esteja na agenda da ISO, de acordo com Jorgensen, Remmen e Mellado (2006), algumas iniciativas melhoraram a compatibilidade entre os diferentes padrões: a ISO 9001 tem um processo focado na melhoria contínua, que é um dos fundamentos dos sistemas de gestão ambiental e de saúde e segurança no trabalho; a ISO 14001 foi reeditada em 2004 para melhorar a coerência com a ISO 9001:2000; o padrão ISO 19011:2002 foi desenvolvido comum para auditoria de sistema de gestão da qualidade e de gestão ambiental .

Segundo Oliveira (1999), mesmo sendo muitos os elementos em comum nos sistemas de qualidade e meio ambiente, tem-se que observar que as normas da série ISO 14000 abordam uma questão mais ampla, envolvendo a sociedade, e o cumprimento da legislação vigente. $\mathrm{O}$ gerenciamento de uma organização exige o envolvimento da alta administração com a comunidade, pois o envolvimento com cliente e colaboradores já é requisito da norma ISO 9001.

Pombo e Magrini (2008) ao apresentarem um panorama das certificações ambientais no Brasil, enfatizam a tendência crescente dos SIGs e apresentam as similaridades entre a ISO 9001:2000, a ISO 14001:2004 e a OHSAS 18001:2007.

As próprias Normas ISO apresentam um quadro de correspondência entre seus requisitos. $\mathrm{O}$ objetivo dessa comparação é demonstrar que ambos os sistemas podem ser utilizados conjuntamente por organizações que já estejam operando uma dessas Normas e desejem integrar ambas.

De acordo com Karapetrovic e Willborn (1998), a integração dos sistemas de gestão pode ocorrer de três formas: implementar primeiro o SGQ e depois o SGA; implementar primeiro o SGA e depois o SGQ; e implementar o SGQ e o SGA simultaneamente. A visão apresentada pelos autores poderia ocorrer, também com outros sistemas de gestão.

De acordo com Oliver e Qu (1999), em virtude das semelhanças entre a ISO 9001 e a ISO 14001, as organizações que possuem os requisitos da qualidade implantados têm mais vantagem em implementar e certificar seu sistema de gestão ambiental devido à fundamentação de requisitos como comprometimento 
da alta direção, melhoria contínua e formalização de procedimentos e registros.

Nesta perspectiva, Bernard et al. (2009) realizaram uma pesquisa com 435 companhias certificadas ISO 14001e ISO 9001 na Espanha, buscando identificar o grau de integração ocorrida. Os resultados mostraram que há uma variação entre integração total, integração parcial ou nenhuma integração, quando se analisam os recursos humanos, a documentação e os procedimentos dos SIGs. Numa visão geral, $79 \%$ das empresas apresentaram integração total. Num levantamento também exploratório, Khanna, Laroyia e Sharma (2009) pesquisam 60 organizações certificadas no norte da Índia, questionando sobre os benefícios e as características da integração dos SGIs.

Campos e Medeiros (2009), por exemplo, focaram o desenvolvimento de um modelo matemático a partir da teoria dos conjuntos para explicar a integração de sistemas de gestão. Segundo os autores, a programação matemática pode ser aplicada como ferramenta para a tomada de decisão de uma integração.

De acordo com Coelho (2000), a integração dos sistemas de gestão de uma organização em um único sistema é uma excelente oportunidade para reduzir custos com o desenvolvimento e manutenção de sistemas separados, ou de inúmeros programas e ações que, na maioria das vezes, se sobrepõem e acarretam gastos desnecessários.

Conforme Douglas e Glen (2000) os benefícios do SGI poderiam ser sintetizados em: redução na documentação, redução nos custos, sinergia nos sistemas de gerenciamento, redução das auditorias e da necessidade de treinamento, melhoramento da comunicação entre departamentos, melhoramento da imagem da empresa.

Chaib (2005) detalha que a simplificação da documentação inclui os manuais, procedimentos operacionais, instruções de trabalhos e registros, atendimento estruturado e sistematizado às legislações ambientais. $\mathrm{O}$ autor acrescenta que as vantagens da implantação de um SGI conferem também:

- Diferencial competitivo: fortalecimento da imagem no mercado e na comunidade empresarial, prática da excelência gerencial por padrões internacionais de gestão, atendimento às demandas do mercado e da sociedade em geral;

- Melhoria organizacional: reconhecimento da gestão sistematizada por entidades externas, maior conscientização das partes interessadas, atuação pró-ativa, evitando-se danos ambientais, melhoria do clima organizacional, maior capacitação e educação dos colaboradores, redução do tempo e de investimentos em auditorias internas e externas;

- Minimização de fatores de riscos: segurança legal contra processos e responsabilidades, segurança das informações importantes para o negócio, identificação de vulnerabilidade nas práticas usuais.

Por outro lado, Carvalho e Maccariello (2003) apontam desvantagens da integração dos sistemas de qualidade e meio ambiente, tais como:

- Sistemas de gestão maiores e um pouco mais documentados, necessitando de mudanças e atualizações constantes;

- Custo inicial de tratamento e/ou remoção de não conformidades elevado, porém com tendência a diminuir com o tempo;

- Mudança no processo ou ampliações faz com que o sistema seja alterado;

- Acidente ou falha operacional mais grave pode vir a afetar a credibilidade do sistema implantado.

Khanna, Laroyia e Sharma (2009) salientam como obstáculos dos SGIs: a falta de suporte da administração; falta de treinamento; as auditorias; a falta de comunicação; as barreiras culturais e; a inexistência de guias específicos para a implementação do SGI.

O que se observa na literatura sobre os SGIs é que existem formas diferentes de integração dos sistemas como Karapetrovic e Willborn (1998) colocam, a integração pode ser em diferentes sistemas de gestão e ainda pode estar integrada em diferentes níveis como mostra o trabalho de Bernard et al. (2009).

No entanto, é entendimento geral que os SIGs devem envolver as diversas áreas das organizações, respeitando-se as especificidades de cada área, atendendo-se às necessidades organizacionais e devendo-se garantir a adesão de todos no processo de gestão pela melhoria contínua (TRONCO et al., 2005).

\section{Metodo de pesquisa}

A pesquisa foi desenvolvida em uma empresa do ramo de confecções têxtil. Esta empresa foi escolhida para a pesquisa, pois estava no final do processo de certificação do sistema de gestão da qualidade, ISO 9001, e interessada em iniciar a implementação do seu sistema de gestão ambiental, ISO 14001.

A pesquisa foi desenvolvida por meio da estratégia estudo de caso (YIN, 2003), em que o pesquisador teve inserção na implementação do sistema de gestão da qualidade e na estruturação do sistema de gestão ambiental.

Os dados coletados foram de fontes primárias e secundárias. Os dados primários vieram da organização, pois foram buscados diretamente na fonte. Quanto aos secundários, estes procedem da literatura, bem como consulta em materiais (manuais, normas, entre outros) existentes na empresa que são utilizados na implantação do SGQ.

Para coletar os dados foram realizadas reuniões e fóruns de estudo quanto à gestão ambiental, com o objetivo de: envolvimento dos gestores dos processos, análise de relatórios de gestão, avaliação 
de conformidades da ISO 9001:2008, entrevistas abertas com os executores e observação in loco dos processos produtivos.

Ainda, como fonte de evidência para o levantamento dos dados relativos ao Sistema de Gestão da Qualidade, foi utilizada a documentação referente à gestão da qualidade, relatórios de participação no PGQP 2007, comunicados, boletins, manual da qualidade, procedimentos dos setores, jornais de circulação interna na empresa, planejamento estratégico dentre outros fornecidos pela empresa.

O delineamento das etapas da pesquisa está apresentado na Figura 1.

\section{Estudo de caso}

A empresa objeto do estudo de caso possui estrutura física própria de $3.000 \mathrm{~m}^{2}$, conta com duas unidades de produção, sendo a Unidade I com dois Prédios e três salas de costura, e a Unidade II com uma sala de costura, além de uma sala designada como "escolinha de costura" para ensino da profissão aos novos colaboradores.

Com uma capacidade produtiva instalada de 500.000 peças por mês, a empresa vem ganhando cada vez mais mercado e clientes, superando as metas estabelecidas. A natureza das atividades da empresa é indústria de confecções, no segmento vestuário, com confecção de moda íntima e fitness voltada para o público feminino. O Quadro 1 resume os principais eventos da empresa, iniciando com a sua fundação, em 1989, até o ano de 2008.

O quadro funcional atual é composto por mais de 700 colaboradores, além disso, a empresa conta com assessorias nas áreas de comércio exterior, comunicação, moda, contabilidade, informática, segurança e medicina do trabalho, industrial e jurídica, e parcerias na área de serigrafia.

A empresa tem como diferencial competitivo de seus principais concorrentes os seguintes fatores: velocidade no desenvolvimento e inovações no design de novos produtos, atendimento aos requisitos específicos de cada cliente, alta tecnologia, qualidade dos produtos, boa aceitação do produto no ponto de venda, credibilidade, preço, transparência, tradição e reconhecimento no mercado.

O processo produtivo da empresa está caracterizado no fluxograma da Figura 2, identificando-se os aspectos ambientais gerados em cada etapa deste processo. Os principais aspectos são os resíduos sólidos papel e plástico das embalagens, o retalho, óleo e ruído.

$\mathrm{O}$ controle destes aspectos ambientais acontece no momento do descarte dos resíduos, sendo que a média é apresentada a seguir:

- Papel e Plástico: 46.000 Kg/ano

- Retalho: $30.000 \mathrm{Kg} / \mathrm{ano}$

- Óleo, Ruído: Não existe um controle destes aspectos.

Avaliando a quantidade de tecido adquirida anualmente pela empresa, o descarte de retalhos representa $25 \%$ do total de tecido comprado, sendo considerado um percentual elevado com relação à questão ambiental, porém, na questão custo, o desperdício percentual é incluído no valor cobrado do cliente.

Devido ao processo de implantação da norma ISO 9001 e a cultura voltada para a qualidade, algumas

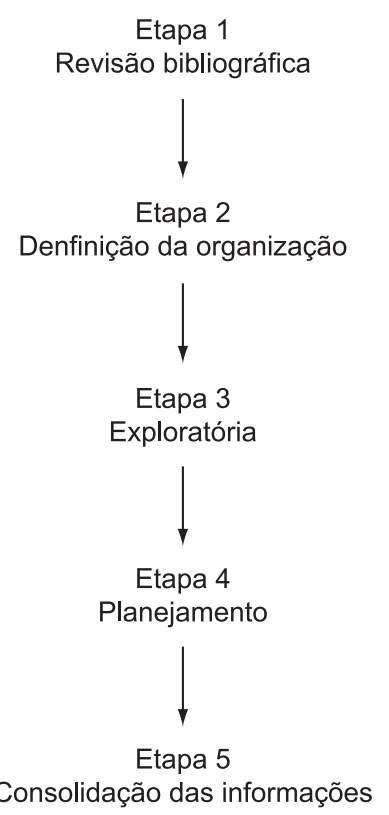

Consulta a livros, periódicos, artigos relacionados à gestão ambiental e gestão da qualidade.

Experiência do autor do estudo, organização em processo de certificação ISO 9001

Entrevistas abertas, reuniões, análise de material na organização que foi foco do estudo - empresa de confecção têxtil.

Reuniões com grupo de trabalho, entrevistas focadas.

Análise do material coletado, avaliação dos relatos e verificação dos relatórios.

Figura 1. Delineamento da pesquisa. 
ações relativas ao meio ambiente já foram implantadas na empresa, entre elas, o repasse do resíduo do retalho à empresa Cetric, que promove seu reaproveitamento para finalidades diversas de cunho social.

As matérias-primas básicas são as usuais de uma indústria de confecções. Está apresentado no Quadro 2 um resumo do consumo médio mensal das principais matérias-primas e insumos utilizados na produção desta empresa.

\section{Integração dos sistemas da qualidade e ambiental}

\subsection{Proposição do Modelo Sistema de Gestão Ambiental integrado ao Sistema de Gestão de Qualidade}

O Quadro 3 apresenta os resultados da integração dos requisitos de ambas as normas, na análise daquilo que foi incorporado do SGA a partir do APRENDIZADO do SGQ, daquilo que foi INTEGRADO e do que NÃO HOUVE INFLUÊNCIA.

\subsubsection{Requisitos gerais do Sistema de Gestão Ambiental}

Inicialmente, há que se definir o escopo para a implementação, ou seja, as condições e limites do SGA. A empresa tem liberdade para definir estes limites, podendo fazê-lo no âmbito da empresa ou parte dela. Na empresa em estudo, que está entre as classificações de empresa de pequeno/médio porte, e levando-se em conta o escopo já definido no SGQ, considerou-se conveniente a abrangência de toda a empresa.

\subsubsection{Planejamento do Sistema de Gestão Ambiental}

Os itens dispostos no planejamento englobam todos os fatores que devem ser levados em consideração quando ocorre a implantação do SGA, sendo eles os aspectos ambientais, requisitos legais, objetivos e metas.

Quadro 1. Histórico da empresa.
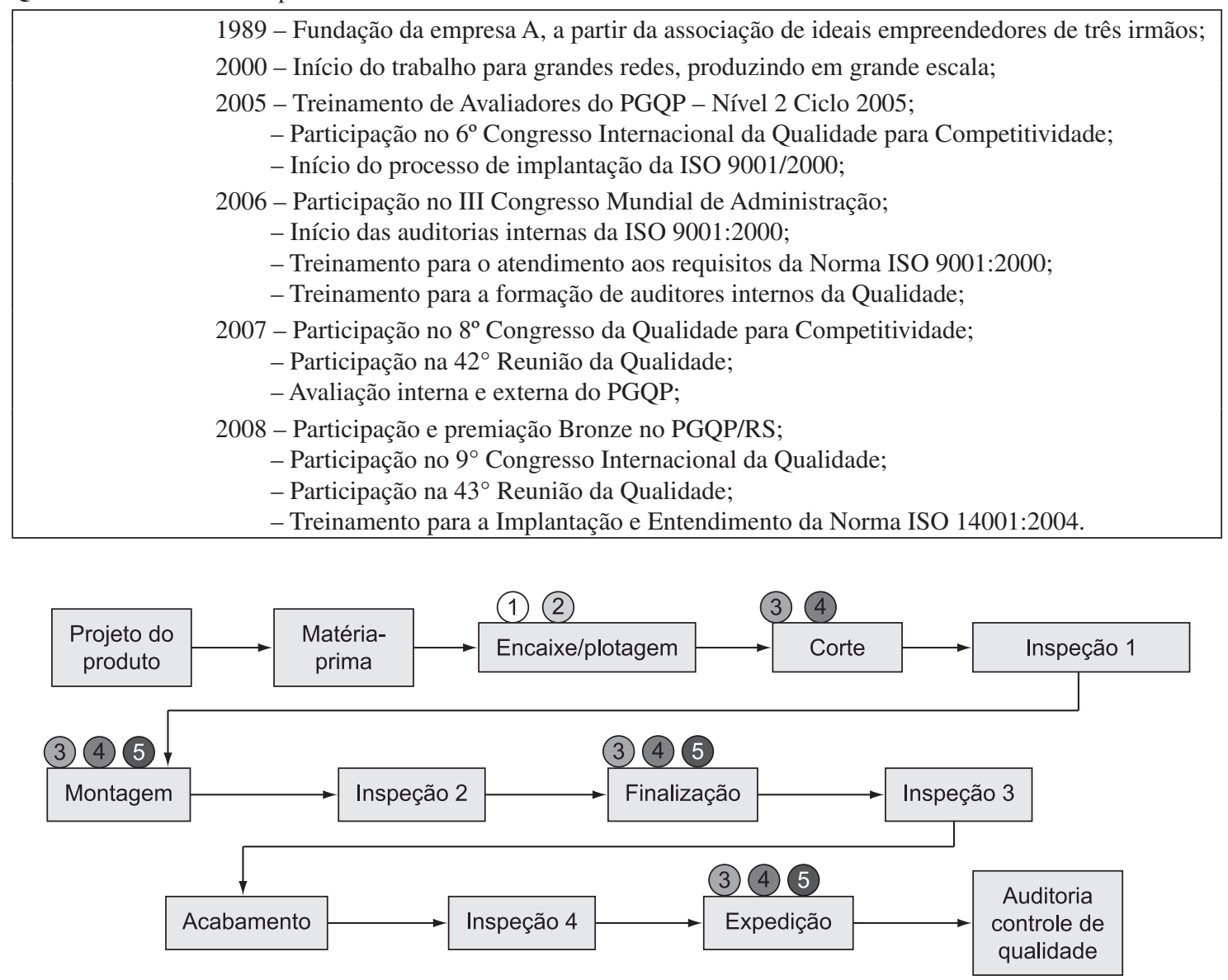

(1) Papel (2) Plástico (3) Retalho (4) Ruído (5) Óleo

Figura 2. Fluxograma da produção e aspectos ambientais. 


\section{A. Aspectos e impactos ambientais}

A empresa deve estabelecer e manter procedimentos para identificar os aspectos ambientais de suas atividades, produtos e serviços, e que estes possam ser por ela controlados, a fim de determinar aqueles que tenham ou possam ter impactos significativos sobre o meio ambiente. A identificação dos aspectos ambientais e da análise dos impactos associados é de suma importância para toda a organização, devido à grande oportunidade de envolvimento de todos os setores com a implementação do SGA. A empresa deve ainda assegurar que os aspectos relacionados aos impactos significativos sejam considerados na definição de seus objetivos ambientais. No quadro 4, apresenta-se a identificação dos aspectos ambientais e seus impactos.

Para a avaliação dos impactos e aspectos, utilizou-se o modelo proposto por Seiffert (2007), com dados da atividade e operação da empresa, caracterização, verificação, avaliação da significância, controles já existentes, legislação regulamentadora pertinente; permitindo assim, a avaliação da importância dos aspectos e impactos ambientais. O objetivo foi definir uma hierarquia dos impactos e aspectos, possibilitando a priorização de medidas preventivas e corretivas.

Dos processos analisados, apenas dois impactos gerados foram considerados significativos: poluição do solo causado pela geração de retalhos e escassez de recursos (energia elétrica), que é utilizada em todos os processos. Sabe-se que a região onde a empresa está instalada é grande produtora de energia elétrica, mas esta não é disponibilizada para a região.

No controle dos impactos significativos, a empresa faz um monitoramento da utilização de energia elétrica, pois além da relevância ambiental ela é um dos custos de produção relevantes. Em relação aos retalhos do processo produtivo, existe um controle operacional, em que todas as sobras são encaminhadas a uma empresa especializada no tratamento destes resíduos.

\section{B. Requisitos legais}

A norma ISO 14001 determina que

[...] a organização deve estabelecer, implementar e manter procedimento para identificar e ter acesso à legislação aplicável e outros requisitos por ela subscritos aplicáveis aos aspectos ambientais de suas atividades, produtos e serviços. (ASSOCIAÇÃO... 2004, p. 13).

$\mathrm{O}$ atendimento a esse requisito apoia o compromisso político da empresa com a conformidade legal e é indispensável ao SGA. Desta forma, a Empresa deverá identificar e ter acesso aos requisitos legais vigentes relativos ao Meio Ambiente. No caso da empresa em estudo, o Quadro 5 apresenta esta legislação.

\section{Definição de objetivos e metas}

Os objetivos e metas foram definidos de acordo com o levantamento de aspectos e impactos ambientais associados às atividades realizadas na empresa. Estes objetivos são propósitos globais para o desempenho ambiental identificados na Política e devem ser relacionados a metas específicas, mensuráveis e com prazo determinado.

Para a empresa, foram definidos três objetivos, cuja responsabilidade cabe aos setores gerenciais e operacionais e são apoiados pela direção da empresa:

- Objetivo 1: Redução de geração de resíduos sólidos:

- Meta 1.1: Reduzir, por meio do controle dos processos internos de encaixe e corte, em 5\% a quantidade total de retalhos. Prazo 1.1: 7 meses. Indicador 1.1: Quantidade (toneladas) de resíduos sólidos gerados por mês.

- Meta 1.2: Reduzir em 15\% o volume de papel descartado no setor administrativo. Prazo 1.2: 3 meses. Indicador 1.2: Volume de papel enviado para reciclagem.

- Objetivo 2: Redução do consumo de recursos naturais:

- Meta 2.1: Reduzir em 8\% o consumo de energia elétrica. Prazo 2.1: 3 meses. Indicador: Consumo de energia elétrica $(\mathrm{kWh})$ mês.

- Meta 2.2: Reduzir em 5\% o consumo de água tratada. Prazo 2.2: 3 meses. Indicador 2.2: Consumo de água $\left(\mathrm{m}^{3}\right)$ mês.

- Objetivo 3: Capacitação dos empregados em temas de meio ambiente:

- Meta 3.1: Capacitar 15\% do efetivo de empregados. Prazo 3.1: 10 meses. Indicador 3.1: Horas treinadas por funcionário em temas de meio ambiente.

\subsubsection{Implementação do Sistema de Gestão Ambiental}

O Programa de Gestão define como os objetivos e metas serão atingidos, bem como quais os recursos e

Quadro 2. Consumo médio de matéria-prima na empresa.

\begin{tabular}{|cccc|}
\hline Insumos / MP & Consumo médio mensal & Caracterização & Estocagem \\
\hline Tecido Light & $3.000 \mathrm{Kg}$ & Poliamida & Prateleiras \\
Elástico Ibérico & $218.000 \mathrm{~m}$ & Poliamida & Caixas \\
Bojo & 90.000 pares & Poliuretano & Caixas \\
Colchete & 85.000 peças & Nylon & Caixas \\
\hline
\end{tabular}


Quadro 3. Correspondência entre a ISO 9001:2008 e a ISO 14001:2004 e resultados da pesquisa. Fonte: Adaptado da ABNT NBR ISO 14001:2004.

\begin{tabular}{|c|c|c|}
\hline ABNT NBR ISO 9001:2008 & & ABNT NBR ISO 14001:2004 \\
\hline Sistema de gestão da qualidade (título somente) & & Requisitos do sistema da gestão ambiental \\
\hline Requisitos gerais & Aprendizado & Requisitos gerais \\
\hline Requisitos de documentação (título somente) & & \\
\hline Generalidades & Aprendizado & Documentação \\
\hline Manual da qualidade & & \\
\hline Controle de documentos & Integrado & Controle de documentos \\
\hline Controle de registros & Integrado & Controle de registros \\
\hline Responsabilidade da direção (título somente) & Aprendizado & \\
\hline Comprometimento da direção & & $\begin{array}{l}\text { Política ambiental } \\
\text { Recursos, funções, } \\
\text { responsabilidades e autoridades }\end{array}$ \\
\hline Foco no cliente & $\begin{array}{l}\text { Não houve } \\
\text { influência }\end{array}$ & $\begin{array}{l}\text { Aspectos ambientais } \\
\text { Requisitos legais e outros } \\
\text { Análise pela Administração }\end{array}$ \\
\hline Política da qualidade & Integrado & Política ambiental \\
\hline Planejamento (título somente) & & Planejamento \\
\hline Objetivos da qualidade & $\begin{array}{l}\text { Aprendizado/ } \\
\text { Integrado }\end{array}$ & Objetivos, metas e programa (s) \\
\hline $\begin{array}{l}\text { Planejamento do sistema de gestão da } \\
\text { qualidade }\end{array}$ & $\begin{array}{l}\text { Aprendizado/ } \\
\text { Integrado }\end{array}$ & Objetivos, metas e programa (s) \\
\hline $\begin{array}{l}\text { Responsabilidade, autoridade e comunicação } \\
\text { (título somente) }\end{array}$ & & \\
\hline Responsabilidade e autoridade & $\begin{array}{l}\text { Aprendizado/ } \\
\text { Integrado }\end{array}$ & $\begin{array}{l}\text { Recursos, funções, } \\
\text { responsabilidades e autoridades }\end{array}$ \\
\hline Representante da direção & $\begin{array}{l}\text { Aprendizado/ } \\
\text { Integrado }\end{array}$ & $\begin{array}{l}\text { Recursos, funções, } \\
\text { responsabilidades e autoridades }\end{array}$ \\
\hline Comunicação interna & Integrado & Comunicação \\
\hline Análise crítica pela direção (título somente) & & \\
\hline Generalidades & Integrado & Análise pela Administração \\
\hline Entrada para análise crítica & Integrado & Análise pela Administração \\
\hline Saídas da análise crítica & Integrado & Análise pela Administração \\
\hline Gestão de recursos (título somente) & & \\
\hline Provisão de recursos & Integrado & $\begin{array}{l}\text { Recursos, funções, } \\
\text { responsabilidades e autoridades }\end{array}$ \\
\hline Recursos humanos (título somente) & & \\
\hline Generalidades & Integrado & $\begin{array}{l}\text { Competência, treinamento e } \\
\text { conscientização }\end{array}$ \\
\hline Competência, conscientização e treinamento & Integrado & $\begin{array}{l}\text { Competência, treinamento e } \\
\text { conscientização }\end{array}$ \\
\hline Infraestrutura & Integrado & $\begin{array}{l}\text { Recursos, funções, } \\
\text { responsabilidades e autoridades }\end{array}$ \\
\hline Ambiente de trabalho & & \\
\hline Realização do produto (título somente) & & Implementação e operação \\
\hline Planejamento da realização do produto & Aprendizado & Controle operacional \\
\hline $\begin{array}{l}\text { Processos relacionados a clientes (título } \\
\text { somente) }\end{array}$ & & \\
\hline $\begin{array}{l}\text { Determinação de requisitos relacionados ao } \\
\text { produto }\end{array}$ & Aprendizado & $\begin{array}{l}\text { Aspectos ambientais } \\
\text { Requisitos legais e outros } \\
\text { Controle operacional }\end{array}$ \\
\hline $\begin{array}{l}\text { Análise crítica de requisitos relacionados ao } \\
\text { produto }\end{array}$ & Aprendizado & $\begin{array}{l}\text { Aspectos ambientais } \\
\text { Controle operacional }\end{array}$ \\
\hline
\end{tabular}


Quadro 3. Continuação...

\begin{tabular}{|c|c|c|}
\hline ABNT NBR ISO 9001:2008 & & ABNT NBR ISO 14001:2004 \\
\hline \multicolumn{2}{|l|}{ Sistema de gestão da qualidade (título somente) } & Requisitos do sistema da gestão ambiental \\
\hline Comunicação com o cliente & Aprendizado & Comunicação \\
\hline \multicolumn{3}{|l|}{ Projeto e desenvolvimento (título somente) } \\
\hline Planejamento do projeto e desenvolvimento & Aprendizado & Controle operacional \\
\hline Entradas de projetos e desenvolvimento & Aprendizado & Controle operacional \\
\hline Saídas de projeto e desenvolvimento & Aprendizado & Controle operacional \\
\hline Análise crítica de projeto e desenvolvimento & Aprendizado & Controle operacional \\
\hline Verificação de projeto e desenvolvimento & Aprendizado & Controle operacional \\
\hline Validação de projeto e desenvolvimento & Aprendizado & Controle operacional \\
\hline $\begin{array}{l}\text { Controle de alterações de projeto e } \\
\text { desenvolvimento }\end{array}$ & Aprendizado & Controle operacional \\
\hline \multicolumn{3}{|l|}{ Aquisição (título somente) } \\
\hline Processo de aquisição & Aprendizado & Controle operacional \\
\hline Informações de aquisição & Aprendizado & Controle operacional \\
\hline Verificação de produto adquirido & Aprendizado & Controle operacional \\
\hline \multicolumn{3}{|l|}{$\begin{array}{l}\text { Produção e fornecimento de serviço (título } \\
\text { somente) }\end{array}$} \\
\hline $\begin{array}{l}\text { Controle de produção e fornecimento de } \\
\text { serviço }\end{array}$ & Aprendizado & Controle operacional \\
\hline $\begin{array}{l}\text { Validação dos processos de produção e } \\
\text { fornecimento de serviço }\end{array}$ & Aprendizado & Controle operacional \\
\hline \multicolumn{3}{|l|}{ Identificação e rastreabilidade } \\
\hline \multicolumn{3}{|l|}{ Propriedade do cliente } \\
\hline Preservação do produto & $\begin{array}{l}\text { Não houve } \\
\text { influência }\end{array}$ & Controle operacional \\
\hline $\begin{array}{l}\text { Controle de dispositivos de medição e } \\
\text { monitoramento }\end{array}$ & & Monitoramento e medição \\
\hline Medição, análise e melhoria (título somente) & & Verificação (título somente) \\
\hline Generalidades & & Monitoramento e medição \\
\hline \multicolumn{3}{|l|}{ Medição e monitoramento (título somente) } \\
\hline \multicolumn{3}{|l|}{ Satisfação dos clientes } \\
\hline Auditoria interna & $\begin{array}{l}\text { Aprendizado/ } \\
\text { Integrado }\end{array}$ & Auditoria interna \\
\hline Medição e monitoramento & Aprendizado/ & Monitoramento e medição \\
\hline & Integrado & $\begin{array}{l}\text { Avaliação do atendimento a } \\
\text { requisitos legais e outros }\end{array}$ \\
\hline Medição e monitoramento de produtos & $\begin{array}{l}\text { Aprendizado/ } \\
\text { Integrado }\end{array}$ & $\begin{array}{l}\text { Monitoramento e medição. } \\
\text { Avaliação do atendimento a } \\
\text { requisitos legais e outros }\end{array}$ \\
\hline Controle de produto não conforme & $\begin{array}{l}\text { Aprendizado/ } \\
\text { Integrado }\end{array}$ & $\begin{array}{l}\text { Preparação e resposta a emergência } \\
\text { Não conformidade, ação corretiva } \\
\text { e ação preventiva }\end{array}$ \\
\hline Análise de dados & $\begin{array}{l}\text { Aprendizado/ } \\
\text { Integrado }\end{array}$ & Monitoramento e medição \\
\hline \multicolumn{3}{|l|}{ Melhoria (título somente) } \\
\hline Melhoria contínua & $\begin{array}{l}\text { Aprendizado/ } \\
\text { Integrado }\end{array}$ & $\begin{array}{l}\text { Política ambiental } \\
\text { Objetivos, metas e programa(s) } \\
\text { Análise pela administração }\end{array}$ \\
\hline Ação corretiva & $\begin{array}{l}\text { Aprendizado/ } \\
\text { Integrado }\end{array}$ & $\begin{array}{l}\text { Não conformidade, ação corretiva } \\
\text { e ação preventiva }\end{array}$ \\
\hline Ação preventiva & $\begin{array}{l}\text { Aprendizado/ } \\
\text { Integrado }\end{array}$ & $\begin{array}{l}\text { Não conformidade, ação corretiva } \\
\text { e ação preventiva }\end{array}$ \\
\hline
\end{tabular}


Quadro 4. Aspectos, impactos e fonte geradora da empresa.

\begin{tabular}{|lll|}
\hline \multicolumn{1}{|c|}{ Processo/etapa } & \multicolumn{1}{c|}{ Aspecto } & \multicolumn{1}{c|}{ Impacto } \\
\hline Processo Produtivo Transporte & Ruído & Poluição Sonora \\
Transporte & Trânsito & Poluição do ar / acidentes \\
Processo Produtivo & Resíduo Sólido - Retalho de tecido & Poluição Solo \\
Processo Produtivo & Resíduo Sólido - Carretel & Poluição Solo \\
Ambulatório Médico & Resíduo Sólido - Ambulatorial & Poluição Solo e águas \\
Rotinas Administrativas & Resíduo Sólido - Administrativo - & Poluição Solo e águas \\
& detalhar papel, cartucho de tinta & \\
Banheiros / Pias & Resíduo Líquido - Esgoto Cloacal & Poluição Solo e águas \\
Processo Limpeza & Resíduo Sólido - Limpeza & Poluição Solo e Águas \\
Atividades diárias de toda a empresa & Utilização de energia & Escassez do recurso \\
Atividades diárias de toda a empresa & Utilização de água & Escassez do recurso \\
Transporte & Queima de combustível & Poluição do ar \\
Fornecedor & Resíduo Líquido - Serigrafia & Poluição águas \\
Processo Produtivo & Utilização de algodão - tecido & Escassez do recurso \\
Compras & & \\
Processo Produtivo Compras & Utilização de poliamida - tecido & Escassez do recurso \\
\hline
\end{tabular}

Quadro 5. Requisitos legais aplicáveis à indústria de confecções.

\begin{tabular}{|c|c|}
\hline Legislação/regulamento & Descrição \\
\hline Constituição Federal do Brasil 1988 & Cap. VI - Meio Ambiente \\
\hline Lei $4.771 / 65$ & Código Florestal \\
\hline Decreto-Lei 1413/75 & Controle de Poluição do Meio Ambiente \\
\hline Lei 9344/97 & Política Nacional de Recursos Hídricos \\
\hline Lei $9966 / 00$ & $\begin{array}{l}\text { Prevenção, controle e fiscalização da poluição causada } \\
\text { por substâncias nocivas }\end{array}$ \\
\hline Lei $9605 / 98$ & Lei de Crimes Ambientais \\
\hline Lei 6938/81 & Política Meio Ambiente - Poluição Sonora \\
\hline Lei 9503 & Código de trânsito \\
\hline Lei 6803/90 & Zoneamento Industrial \\
\hline CONSEMA 128 & Efluentes líquidos \\
\hline NBR 10.004 & Classificação de Resíduos \\
\hline NBR 11.174 & Armazenamento de Resíduos Classe II e III \\
\hline NBR 12.235 & Resíduos Perigosos \\
\hline Resolução CONAMA 001/86 & Avaliação de Impacto Ambiental \\
\hline Resolução CONAMA 002/90 & Programa de Silêncio \\
\hline Resolução CONAMA 237/97 & Licenciamento Ambiental \\
\hline Resolução CONAMA 001/90 & Ruído \\
\hline Decreto 99274/ & $\begin{array}{l}\text { Criação de Estações Ecológicas e Áreas de Proteção } \\
\text { Ambiental e sobre a Política Nacional do Meio Ambiente }\end{array}$ \\
\hline Lei $11520 / 00$ & Código Estadual do Meio Ambiente \\
\hline Portaria GM 124/80 & $\begin{array}{l}\text { Estabelecem normas para a localização de indústrias } \\
\text { potencialmente poluidoras junto às coleções hídricas }\end{array}$ \\
\hline
\end{tabular}

meios necessários para o seu atendimento. A empresa deve assegurar que os recursos administrativos (financeiros e equipamentos) e humanos (treinamento) sejam adequadamente controlados e incorporados ao planejamento. Além disso, para atingir os objetivos propostos, a empresa deve designar as responsabilidades, definir o cronograma, determinar os locais e o método adotado para atingir cada objetivo.

\section{A. Estrutura e responsabilidades}

A designação de responsabilidades é fundamental para o sucesso da implementação do SGA, sendo que a responsabilidade final, e mais importante, é da alta direção da empresa.

Um grupo de trabalho composto por representantes dos setores administrativos e operacionais foi definido a partir da análise do escopo do SGA, bem como 
as responsabilidades já exercidas no SGQ visando evidenciar a integração dos sistemas e com o objetivo de facilitar a aplicabilidade do Sistema em toda a Empresa. Assim, em alguns casos, acumularam-se funções nas pessoas que já desempenhavam o SGQ, para garantir a integração dos dois sistemas.

\section{B. Treinamento, conscientização e competência}

Como requisito da norma ISO 14001:2004, a empresa definiu que os treinamentos seriam ministrados aos seus funcionários, de modo a desenvolver as competências e disseminar a cultura de preservação ambiental. Os treinamentos envolveriam palestras, seminários, cursos e eventos, a fim de incentivar o envolvimento ao SGA e o entendimento das questões a ele relacionadas.

Neste item, a integração dos sistemas está relacionada ao uso da sistemática já existente de aplicação de treinamento no SGQ. Assim, para a avaliação destes treinamentos foi utilizada a mesma metodologia do SGQ, realizando a avaliação da eficácia dos eventos e verificando a conformidade com os objetivos iniciais e com a realização do trabalho posteriormente ao treinamento (observação do superior direto). Os treinamentos dos dois sistemas de gestão continuaram ocorrendo com abordagens específicas a cada tema de interesse.

\section{Comunicação}

O sistema de comunicação é uma especificação relacionada aos meios de comunicar as partes interessadas do andamento monitorado do SGA. A organização deve estabelecer e manter procedimentos para realizar a comunicação interna entre os vários níveis da organização, atuar sobre o recebimento, documentação e respostas às comunicações pertinentes das partes interessadas. Para a realização da comunicação, foram definidos os mesmos meios já utilizados no SGQ, podendo citar: cartazes, murais internos, e-mail, $\mathrm{SAC}$, site, treinamentos e reuniões dos comitês de Gestão.

\section{Documentação do Sistema de Gestão Ambiental}

A documentação do SGA representa um subsistema com a função de descrever os principais elementos do sistema de gestão e a interação entre eles. Ela pode ser disposta em papel ou meio eletrônico, porém, para a Empresa foi utilizada a mesma estrutura documental, em papel, do SGQ. O elemento mais significativo deste subsistema é o Manual, que funciona como um documento mestre no SGA, estando nele sintetizada toda a estrutura e interligações do sistema.

Toda a documentação do sistema de gestão ambiental foi adaptada ao sistema de gestão da qualidade, já existente e consolidado na Empresa. Conforme disposto na Norma ISO 14001:2004, a acepção de um manual formal não é requisito obrigatório, porém é recomendável e foi adotado visando à facilidade na adaptação. Os documentos, formulários e registros do SGA foram padronizados de acordo com os documentos do SGQ, utilizando as formatações específicas e seguindo as normas de aprovação e revisão.

\section{E. Controle operacional}

Os controles operacionais representam a alternativa para o gerenciamento dos impactos ambientais significativos, sendo documentados em procedimentos visando a padronização. Os procedimentos operacionais foram descritos utilizando os próprios procedimentos e instruções de trabalho do SGQ da empresa, incluindo neles as especificações e condições controladas necessárias à gestão ambiental. Houve uma completa integração dos requisitos das duas normas nos procedimentos operacionais.

\section{F. Preparação e atendimento a situações de emergência}

Considerando o tipo de processo produtivo utilizado e as condições da empresa, há poucas possibilidades de acidentes ambientais, porém criou-se o comitê ambiental com a responsabilidade de identificar os cenários potenciais de emergência e realizar as simulações em caso de identificação desta necessidade.

\subsubsection{Verificação e ação corretiva e preventiva}

Abordando a verificação do SGA, este item engloba todos os processos relativos a monitoramento e medição, avaliação do atendimento aos requisitos legais, não conformidades, ação corretiva/preventiva, controle de registros e auditoria interna. Considerando a fase final de implantação do SGQ, a Empresa possui o subsistema de monitoramente e medição implantado, facilitando a adequação e atendimento aos requisitos da ISO 14001.

\section{A. Monitoramento e medição}

O procedimento operacional utilizado para a medição e monitoramento do SGQ apenas foi alterado incluindo os controles das atividades que causam impacto ambiental, indicadores referentes aos objetivos do plano de ação. O monitoramento segue o padrão utilizado no SGQ - Indicadores de Gestão que são acompanhados mensalmente pelo setor da qualidade, que busca as informações e repassa aos envolvidos no processo. 


\section{B. Avaliação do atendimento a requisitos legais e outros}

O procedimento de avaliação do atendimento aos requisitos legais aplicáveis foi incluído no Manual da Qualidade, incorporando a metodologia de controle e monitoramento. Esta metodologia foi incorporada à avaliação de documentos externos do SGA da empresa, realizada por meio da Lista Mestra, adicionada a definição de um responsável pela avaliação e o registro deste controle.

\section{Não conformidade, ação corretiva e ação preventiva}

Para o atendimento a este item, foi utilizado o Procedimento Operacional 02 - Controle de Não Conformidades, Ação Corretiva e Preventiva, já utilizado no SGQ da empresa, sendo apenas incluídas as questões referentes ao Sistema de Gestão Ambiental. Este item é integrado, utilizando-se os mesmos procedimentos do SGQ.

\section{Controle de registros}

O controle de registro já é utilizado pela empresa, seguindo o Procedimento Operacional 01 - Emissão de Documentos e Controle de Registros, sendo apenas incluídas as questões referentes ao Sistema de Gestão Ambiental, e tendo como responsável por este controle o setor de qualidade. Este item é integrado, utilizando-se os mesmos procedimentos do SGQ.

\section{E. Auditoria interna}

Realizadas desde 2006, as auditorias internas da empresa abrangem todos os requisitos do SGQ, seguindo o Procedimento Operacional 09 - Auditorias Internas, e tendo 15 auditores internos treinados para estas verificações. Para a adequação a este item do SGA, apenas foram incluídas as questões referentes ao Meio Ambiente, Resíduos, Objetivos e Metas Ambientais, Requisitos Legais, entre outros relativos ao Sistema de Gestão Ambiental, mantendo a estrutura e os registros já existentes.

\section{F. Análise crítica pela alta direção}

A Alta Direção da empresa realiza análises críticas semestrais desde o ano de 2006, conforme o Procedimento Operacional - Análise Crítica da Direção, sendo que, para a conformidade com os requisitos da Norma ISO 14001, foram incluídos os itens relativos ao Sistema de Gestão Ambiental, conforme itens: Resultados das Auditorias Ambientais; Comunicação com os públicos externos; Repasse do desempenho ambiental da empresa; Avaliação dos objetivos e metas ambientais; Inclusão das Ações Corretivas e Preventivas Ambientais. Todas as reuniões de análise crítica são registradas em ata própria e arquivadas no setor da qualidade da empresa.

\subsection{Análise da integração dos sistemas}

A bibliografia mostrou que algumas das principais motivações da integração dos sistemas são o diferencial competitivo, a melhoria organizacional, devido à redução no tempo despendido na manutenção dos diferentes sistemas de gestão existentes e a minimização dos fatores de riscos ambientais e relativos à saúde e segurança do trabalho.

Esta pesquisa, por sua vez, possibilitou constatar que a implementação de um SGA sobre um SGQ existente traz benefícios significativos para uma empresa do ramo de confecções e oportuniza algumas facilidades de implantação e coerência com os processos já adotados. Apesar das normas ISO 14001 e ISO 9001 serem similares, facilitando a integração a fim de melhorar o desempenho de ambos os sistemas, deve-se assegurar o foco no atendimento dos objetivos de cada uma. É nesse sentido que foi elaborado este modelo para a empresa em estudo, procurando beneficiá-la em termos de custos e gestão.

A gestão da qualidade tem foco no produto, a obtenção de resultados e padronização dos procedimentos em todos os setores da empresa e no atendimento aos requisitos dos clientes. Em suma, todos os processos devem ser planejados e estruturados para uma perfeita realização do produto. A Empresa iniciou o processo de implantação do SGQ em virtude das exigências do mercado quanto a certificações que atestam as preocupações das empresas com os seus clientes, acionistas e sociedade. A necessidade de ter seu processo de gestão certificado foi uma visão da alta administração desta empresa, como forma de manter a competitividade e acompanhar as tendências de mercado, por meio da melhoria contínua.

Em relação ao SGQ, o enfoque é diferente, analisam-se os aspectos ambientais, identificando-os para, posteriormente, atender aos requisitos legais e planos de emergência relacionados a estes. Pensando nestes aspectos, é que se propôs uma implantação do SGA baseado no SGQ, devido à existência de uma integração nos sistemas de gestão. Verificou-se que esta implantação conjunta traz alguns benefícios, corroborando assim com a visão de Chaib (2005): a redução de custos, simplificação da documentação (os manuais, procedimentos operacionais, instruções de trabalhos e registros, atendimento estruturado e sistematizado às legislações ambientais).

Além disso, a integração dos sistemas traz economia de tempo em pesquisa e construção do sistema, economia de custos devida à combinação das auditorias e economia de horas/homem na sua implantação, como salientam Seiffert (2007) e Coelho (2000). 
Percebe-se, então, que esta integração pode resultar em ganhos, tanto de custos como de tempo.

Na estruturação do SGA, os requisitos com maior facilidade de integração dizem respeito a controle de documentos, controle de registro, auditorias internas, análise crítica da direção, não conformidades e ação corretiva/preventiva e comunicação, que são atendidos com a implantação do SGQ.

Mesmo com a nova versão da norma ISO 9001, aprovada em 28 de novembro de 2008 e válida a partir de Dezembro de 2008, que substitui a versão 2000, as constatações feitas neste trabalho são relevantes, por ter sido revisada apenas a fim de aumentar a sua clareza, sem introduzir novos requisitos. Além disso, outra finalidade da revisão foi de aumentar a compatibilidade com a ISO 14001.

Outro benefício diz respeito ao aspecto mercadológico, pois, com a implementação de um Sistema de Gestão Ambiental e de Qualidade integrados, as possibilidades de incremento nas relações comerciais com novos clientes, locais ou regionais, aumentam consideravelmente. Aliado ao desenvolvimento comercial, há também o efeito do marketing positivo, decorrente da "venda" da imagem de uma empresa preocupada com as questões de meio ambiente e saúde e segurança do trabalho. Em um ambiente de extrema competitividade empresarial, a implementação do SGA integrado com o SGQ em organizações do ramo de confecções pode servir para reafirmar, perante as partes interessadas - clientes, órgãos fiscalizadores e comunidade - a preocupação que têm com esses assuntos, conferindo-lhes credibilidade.

Outro benefício é em relação ao aspecto mercadológico, pois se torna um diferencial competitivo, fortalece a imagem da empresa e marca no mercado e na comunidade empresarial (CHAIB, 2005). É um sinal de que a organização procura a excelência gerencial por padrões internacionais de gestão, atendimento às demandas do mercado e da sociedade em geral.

Salienta-se que em qualquer programa de melhoria ou mudança cultural na organização deve acontecer, de preferência, por meio do planejamento estratégico. Deve-se prever estas melhorias e mudanças, bem como será sua implementação. Neste sentido, é relevante abordar que a empresa estudada possuía uma caminhada de seis anos de construção e melhoria de seu Planejamento Estratégico, tendo este como uma cultura da alta direção e colaboradores.

Outro aspecto a levar-se em conta no SGA são os elementos de uma cadeia de produção, pois, desde a industrialização de insumos e processamento de produtos até o transporte, recebimento e armazenamento, afetam diretamente o meio ambiente. Com a avaliação dos aspectos e impactos ambientais da empresa, foi possível verificar esta consideração, em que os aspectos são provenientes desde a matériaprima, com a utilização do algodão e da poliamida, até a geração de resíduos, provenientes do processo produtivo, que neste caso avalia-se como significativo o resíduo de tecido. Nesta gama de impactos e aspectos que atingem o meio ambiente, constatou-se a importância de avaliá-los de acordo com a sua significância, visto que as suas consequências, frequências e probabilidade de acontecimento alteram o seu grau de real impacto sobre o meio ambiente e que apenas alguns são de real significância e devem ser controlados.

Na elaboração deste estudo, ficaram evidentes as facilidades advindas da integração: economia de tempo na elaboração dos procedimentos, já que se utilizou o mesmo sistema de documentos; facilidade na avaliação dos impactos e aspectos ambientais já que os processos estavam mapeados; atendimento às legislações vigentes devida à contínua avaliação dos requisitos legais; redução de custos com a certificação integrada; adoção de uma Política de Gestão Única, envolvendo as questões da qualidade e ambiental.

As semelhanças entre as duas normas e as facilidades de implantação aumentam a busca pelas certificações integradas. Conforme relatos dos executivos do órgão certificador da empresa em estudo, citados anteriormente, esta é uma das modalidades de certificação que está crescendo cada vez mais, justamente em função de sua compatibilidade.

Além das facilidades operacionais, também foram percebidas durante a realização do trabalho algumas outras vantagens, voltadas à imagem da empresa perante a comunidade no que tange à responsabilidade ambiental. A inclusão de uma coluna sobre gerenciamento de resíduos no Jornal Interno da empresa, informando todos os colaboradores sobre o principal resíduo gerado, foi uma ação que partiu da equipe do Comitê de Responsabilidade Sócio Ambiental. A aquisição do software especializado no controle de enfesto e treinamento dos colaboradores responsáveis iniciaram a conscientização e melhoria do aproveitamento do tecido ainda na sua fase inicial.

Por outro lado também pode ser percebida uma desvantagem no que se refere à gestão integrada dos sistemas: é muito mais passível de incluir procedimentos ou instruções irrelevantes no processo, que acabariam por torná-lo maior que o necessário, ou seja, a facilidade de integração é tanta, que se a empresa não controlar e verificar a real necessidade de emissão pode-se ter um sistema inchado e moroso.

Perceberam-se também algumas desvantagens da integração dos sistemas de qualidade e meio ambiente, tais como: sistemas de gestão maiores e um pouco mais documentados, necessitando de mudanças e atualizações constantes; custo inicial de tratamento e/ou remoção de não conformidades elevado, porém com tendência a diminuir com o tempo; mudança no processo ou ampliações faz com que o sistema seja alterado; acidente ou falha operacional mais grave pode vir a afetar a credibilidade do sistema implantado. 


\section{Conclusões}

A estratégia usada nesta pesquisa é a mais encontrada nos estudos de casos sobre SGIs, a implantação do SGA a partir do SGQ, isto porque é comum que as empresas tenham primeiro seu sistema de gestão da qualidade.

Os SGIs são uma tendência crescente e irreversível, em que as semelhanças dos sistemas favorecem toda e qualquer abordagem de integração.

Dois pontos principais foram observados ao longo deste trabalho, o primeiro, a forma como se integraram os dois sistemas, e se pôde concluir que nem sempre a empresa integrou, mas sim usou o seu aprendizado e suas rotinas. $\mathrm{O}$ segundo ponto foi a identificação dos aspectos positivos e negativos do SIG, que de maneira geral foi ao encontro do que os estudos anteriores já haviam observado.

Em que pese cada caso em particular, há vantagens e desvantagens desta integração que devem ser conhecidas e consideradas pelas empresas. Este trabalho trouxe contribuições práticas para a empresa em estudo e para a academia como relato de estudo de caso. Quanto ao modelo desenvolvido neste trabalho este poderá ser adaptado a outras organizações para que se utilize na implantação de um SGQ e SGA integrados em outra empresa, que por ventura queira buscar estas certificações. De maneira geral, a pesquisa tem um amplo valor na sua experiência e transferibilidade para empresas do mesmo setor.

\section{Referências}

ASSOCIAÇÃO Brasileira da Indústria Têxxtil e de Confecções - ABIT. Disponível em: <http://www.abit.org.br>. Acesso em: 12 dez. 2008a.

ASSOCIAÇÃO BRASILEIRA DE NORMAS TÉCNICAS - ABNT. NBR ISO 14001:2004. Sistema de gestão ambiental: requisitos com orientações para uso. Rio de Janeiro: ABNT, 2004.

ASSOCIAÇÃO BRASILEIRA DE NORMAS TÉCNICAS - ABNT. NBR ISO 31000:2010. Gestão de Riscos Princípios e diretrizes. Rio de Janeiro: ABNT, 2010.

ASSOCIAÇÃO BRASILEIRA DE NORMAS TÉCNICAS - ABNT. NBR ISO 9001:2008. Sistemas de gestão da qualidade. Rio de Janeiro: ABNT, 2008b.

BERNARD, M. et al. How integrated are environmental, quality and other standardized management systems? An empirical study. Journal of Cleaner Production, p. 742-750, 2009.

BRITISH STANDARDS INSTITUTION. OHSAS 18001: occupational health and safety assessment series. London, 2007.

CAMPOS, C. A. O.; DE MEDEIROS, D. D. Um modelo de integração de sistemas de gestão. Produção, v. 19, n. 1, p. 70-86, 2009.

CARVALHO, P. R. S.; MACCARIELLO, F. M. Certificação de sistema de gestão integrado: qualidade e meio ambiente de unidades de negócios com apoio de unidades corporativas: uma experiência integrada. 2003. Disponível em: <http://biblioteca.iapg.org.br/iapg/ArchivosAdjuntos/ CongressodeCalidad/126.pdf >. Acesso em: 22 fev. 2008.

CENTRO DA QUALIDADE, SEGURANÇA E PRODUTIVIDADE - QSP. Disponível em: <http:// www.qsp.org.br>. Acesso em: 12 nov. 2008.

CHAIB, E. B. D'A. Proposta para implementação de sistema de gestão integrada de meio ambiente, saúde e segurança do trabalho em empresas de pequeno e médio porte: um estudo de caso da indústria metal-mecânica. Dissertação (Mestrado)-COPPE/UFRJ, Rio de Janeiro, 2005.

COELHO, E. J. M. Sistema de gestão integrada: qualidade, saúde e segurança e meio ambiente. Dissertação (Mestrado)-UNICAMP, Campinas, SP, 2000.

DOUGLAS, A.; GLEN, D. Integrated management systems in small and medium enterprises. Total Quality Management, v. 11, p. 686-690, 2000.

GAZETA MERCANTIL. Análise setorial: fiação, tecelagem, malharia. São Paulo, 1999. (Panorama Setorial, V. II).

GRAEL, P. F. F.; OLIVEIRA, O. J. Sistemas certificáveis de gestão ambiental e da qualidade: práticas para integração em empresas do setor moveleiro. Produção, v. 20, n. 1, p. 30-41, 2010.

JORGENSEN, T. H.; REMMEN, A.; MELLADO, M. D. Integrated management systems - three different levels of integration. Journal of Cleaner Production, v. 14, n. 8, p. 713-722, 2006.

KARAPETROVIC, S.; WILLBORN, W. Integration of quality and environmental management systems. The TQM Magazine, v. 10, n. 3, p. 204-213, 1998.

KHANNA, H.; LAROYIA, S. C.; SHARMA, D. D. A Survey on Indian Experience on Integrated Management Standards (IMS). International Journal for Quality Research, v. 3, n. 3, 2009.

LORENZI, S. IBGE detecta reação de máquinas e vestuário. Desafios em Desenvolvimento, v. 5, 2007. Disponível em: <http://www.ipea.gov.br/003/00301009. jsp?ttCD_CHAVE=2216>. Acesso em: 21 fev. 2008.

MELO, A. R. Otimização do reuso de água em lavadores contínuos da indústria têxtil. Dissertação (Mestrado)PPGEQ/UFSC/CT, Florianópolis, SC, 2005.

OLIVEIRA, F. B. Implantação e prática da gestão ambiental: discussão e estudo de caso. Dissertação (Mestrado)-UFRGS, Porto Alegre, RS, 1999.

OLIVER, J.; QU, W. Cost of quality reporting: some Australian evidence. Journal of Applied Quality Management, v. 2, n. 2, p. 233-250, 1999.

POMBO, F.; MAGRINI, A. Gestão \& Produção, v. 15, n. 1, p. 1-10, 2008.

SEIFFERT, M. ISO 14001 Sistemas de gestão ambiental: implantação objetiva e econômica. 3. ed. São Paulo: Atlas, 2007.

TRONCO, C. R. et al. Sistema de gestão integrado de qualidade, meio ambiente, saúde e segurança e responsabilidade social - SGI: uma experiência de implantação. In: SIMPEP, 12., Bauru, SP, 2005.

VIANA, F. L. E.; ROCHA, F. E. V; NUNES, F. R. M. A indústria têxtil na região nordeste: gargalos. Potencialidades e desafios. Produção Online, v. 8, n. 3, 2008.

YIN, R. K. Case study research: design and methods. 3. ed. Newbury Park: SAGE, 2003. 